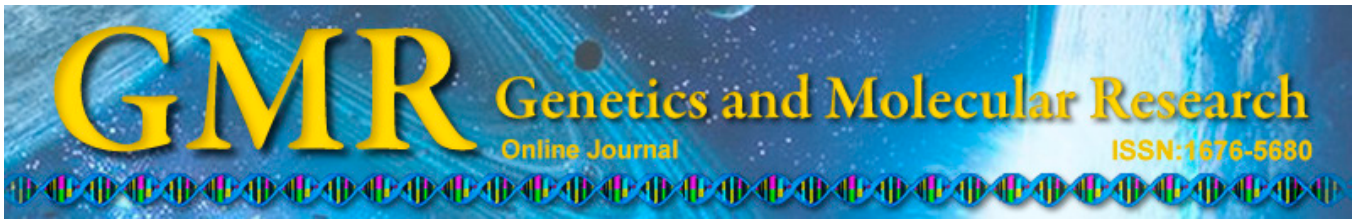

\title{
Inheritance and quantitative trait locus analysis of low-light tolerance in cucumber (Cucumis sativus L.)
}

\author{
D.D. Li ${ }^{1,2}$, Z.W. Qin ${ }^{1,2}$, H. Lian', G.B. Yu' ${ }^{1}$, Y.Y. Sheng ${ }^{1}$ and F. Liu ${ }^{1}$ \\ ${ }^{1}$ College of Agronomy, Heilongjiang Bayi Agricultural University, Daqing, \\ Heilongjiang, China \\ ${ }^{2}$ College of Horticulture, Northeast Agricultural University, Harbin, \\ Heilongjiang, China \\ Corresponding author: D.D. Li \\ E-mail: lidandan342@126.com.cn
}

Genet. Mol. Res. 14 (3): 10609-10618 (2015)

Received February 28, 2015

Accepted June 26, 2015

Published September 9, 2015

DOI http://dx.doi.org/10.4238/2015.September.9.2

\begin{abstract}
The low-light tolerance index was investigated in a set of $123 \mathrm{~F}_{2: 3}$ lines during the seedling stage across 2 seasons, and the heredity of low-light tolerance was assessed via different genetic analysis methods. The results of the classical analysis showed that low-light tolerance is controlled by an additive-dominant polygene, and the polygenic inheritance rate of separate generations was $>30 \%$. In addition, 5 quantitative trait loci (QTLs) exhibited a lowlight tolerance index across both seasons, including 2 QTLs (Llti1.1 and Llti1.2) on the 1st linkage group (variances of 6.0 and $9.5 \%$ ) and 3 QTLs (Llti2.1, Llti2.1, and Llti2.1) on the 2nd linkage group (variances of 10.1-14.0\%). The classical analysis method and QTL information on the heredity of low-light tolerance showed that it is controlled by several major genes and a mini-polygene. The results
\end{abstract}


will facilitate the breeding of resistance to low-light stress in cucumber.

Key words: Cucumber (Cucumis sativus L.); Low-light tolerance; Seedling; Classical genetic analysis; QTLs

\section{INTRODUCTION}

Cucumber (Cucumis sativus L.) is one of the most important vegetable plants grown worldwide, and increasing yields from cucumber plants are necessary. However, low-light intensity is a stressor that leads to major yield losses in northern regions. Plants under low-light stress exhibit slower growth rates, higher fruit abscission rates, and declines in production (Liebig and Krug, 1991). The low-light tolerance of plants is a complex trait, and the mechanisms for expression and/or inheritance are not well understood.

Several attempts have been made to apply both physiological and morphological techniques in cucumber to develop effective screening methods for low-light tolerance (Ma et al., 1997). The tolerance index is a direct evaluation method in plants; for example, the chilling injury index is obtained by classifying the chilling injury level and is used to evaluate chilling tolerance (Liu et al., 2009). The low-light tolerance index is regarded as the most important and intuitive index evaluated (Li et al., 2009a); thus, it is crucial in understanding the genetic characteristics related to the heredity of low-light tolerance in cucumber. Considerable work has been dedicated to breeding large numbers of cucumber cultivars with high yield and quality. There have been many studies investigating the traits related to lowlight stress in cucumber, including genetic reports (Li et al., 2009b), physiological research (Li et al., 2006), and quantitative trait locus (QTL) analyses of the chlorophyll content in cucumber seedlings under low-light stress (Li et al., 2010). Moreover, an additional 5 QTLs related to leaf area growth in cucumber seedlings have been detected under low-light stress, including la-1, la-2, la-3, la-4, and la-5 (Zhang et al., 2004). However, there have been no reports on low-light tolerance, and it is necessary to conduct heredity and QTL analyses of low-light tolerance in cucumber.

Recent technological advances have accelerated the development of genetic mapping and QTL analyses in several crop species to include the QTL detection of important horticultural traits (Li et al., 2008), resistance to powdery mildew in cucumber (Liu et al., 2008), stalk tunneling in maize (Krakowsky et al., 2004), and bacterial leaf streak in rice (Oryza sativa L.; Tang et al., 2000). For example, the location of $F$ and $d e$ was identified by genetic linkage and associated with the simple sequence repeat (SSR) loci CSWCT28 and CSWCTT14 at 5.0 and $0.8 \mathrm{cM}$, respectively (Fazio et al., 2003). Four QTLs for powdery mildew resistance have been identified (i.e., pm1.1, pm2.1, pm4.1, and pm6.1; Liu et al., 2008). A total of 36 QTLs controlling collateral characteristics have been reported, and the total phenotypic variation was 3.1-32.3\% (Zhang et al., 2010).

A limited number of QTLs related to low-light tolerance have been reported (Li et al., 2010). In this study, we analyzed the hereditary and QTL effects via classical genetic and mapping methodologies in order to describe, in depth, the genetic characteristics and identify the QTLs related to low-light tolerance. The identification of QTLs for low-light tolerance traits may be useful in marker-assisted breeding of cucumber cultivars. 


\section{MATERIAL AND METHODS}

\section{Plant materials}

The cucumber low-light stress-tolerant line $\mathrm{M}_{22}$ was crossed with the low-light sensitive line $\mathrm{M}_{14} \cdot \mathrm{M}_{22}$ grew normally and exhibited acclimation when exposed to low-light stress. In contrast, $\mathrm{M}_{14}$ was a shorter plant with severe abnormalities. The parents were selected after screening a large number of cucumber germplasms native to northern China, southern China, and Europe. The generations $\mathrm{F}_{1}, \mathrm{~B}_{1}$, and $\mathrm{B}_{2}$ were obtained from the parents. The $\mathrm{F}_{1}$ generation obtained from the crossing of $\mathrm{M}_{22}$ and $\mathrm{M}_{14}$ was self-pollinated to produce $152 \mathrm{~F}_{2}$ progeny, which were then self-pollinated by single-seed descent to obtain $123 \mathrm{~F}_{2: 3}$ families.

\section{Field evaluation and plant characteristics}

The 2 parental lines (i.e., $\mathrm{M}_{22}$ and $\mathrm{M}_{14}$ ), their $\mathrm{F}_{1}$ generation, and the $\mathrm{F}_{2: 3}$ families were evaluated in a greenhouse at the Horticulture School, BaYi Agricultural University, Daqing, China. The $\mathrm{F}_{2: 3}$ families were grown in 2 seasons, including the autumn of 2012 (A) and spring of 2013 (S). The soil media was comprised of 25,25 , and $50 \%$ peat, cinder, and perlite, respectively. The 6 generation groups of $\mathrm{P}_{1}, \mathrm{P}_{2}, \mathrm{~F}_{1}, \mathrm{~B}_{1}, \mathrm{~B}_{2}$, and $\mathrm{F}_{2}$, and the $\mathrm{F}_{2: 3}$ families were arranged in a randomized complete block design with 3 replications. Each replicate of $\mathrm{P}_{1}, \mathrm{P}_{2}$, and $\mathrm{F}_{1}$ had 10 plants; there were 20 plants for $\mathrm{B}_{1}$ and $\mathrm{B}_{2}$ and 40 plants for $\mathrm{F}_{2}$ and the $\mathrm{F}_{2: 3}$ families. The individual plants were planted in a bowl (base area: $8 \times 8 \mathrm{~cm}$ ) and spaced $5 \mathrm{~cm}$ apart from each other. Evaluation of the low-light tolerance index during the seedling stage was carried out under low-light intensity.

Low-light intensity was simulated by double layers of havelock in the greenhouse, with an average daylight intensity of $\sim 100 \mu \mathrm{mol} \cdot \mathrm{m}^{-2} \cdot \mathrm{s}^{-1}$ and a day/night average temperature of $25^{\circ} / 15^{\circ} \mathrm{C}$. The temperature was regulated using heating equipment and aeration. A 30-day low-light treatment was carried out during the two-leaf stage of the seedlings.

\section{Design method of the low-light tolerance index}

The low-light tolerance index was obtained by design formulas after statistics were performed on 6 generations of plants, with samples from every grade (i.e., 1st-4th, defined below) under the low-light treatment. We divided the degree of damage to cucumber seedlings under low-light stress into 4 (i.e., 1st-4th) grades. The grades were characterized as follows: 1 st) a cotyledon that hangs down gently, only a few green leaves gently withdrawn, and excessive plant growth; 2 nd) etiolation of $50 \%$ of the cotyledons and a chlorotic leaf that can turn green after exposure to light; $3 \mathrm{rd}$ ) complete necrosis of the cotyledons, the number of chlorotic leaves is $>50 \%$, which cannot turn green after exposure to light, and the ability for the top portion of the plant to continue growth; and 4th) complete plant death.

$$
\begin{aligned}
& \text { Low-light inhibition index }=\sum \mathrm{Xa} /\left(\mathrm{n} \sum \mathrm{x}\right) \text { or } \\
& \text { Low-light inhibition index }=\left(\mathrm{X}_{1} \times \mathrm{a}_{1}+\mathrm{X}_{2} \times \mathrm{a}_{2}+\mathrm{X}_{3} \times \mathrm{a}_{3}+\ldots \mathrm{X}_{\mathrm{N}} \times \mathrm{a}_{\mathrm{n}}\right) /\left(\mathrm{n} \sum \mathrm{x}\right)
\end{aligned}
$$

where $X_{1}, X_{2}, X_{3}, \ldots X_{N}$ are the damaged numbers of every grade; $a_{1}, a_{2}, a_{3}, \ldots a_{n}$ are the damaged grades; $n$ is the highest grade $=4$; and $\sum_{X}$ indicates all plants $=10$. 


\section{Marker analysis}

SSR marker (Ren et al., 2009) and sequence-related amplified polymorphism (SRAP) (Li and Quiros, 2001) technologies were selected for genomic analyses of the parents. Leaves (weight: approximately $0.5 \mathrm{~g}$ ) from 2-week-old $\mathrm{F}_{2}(123), \mathrm{F}_{1}$, and parent seedlings were collected and preserved in an ultra-low temperature freezer. The tissue was then immediately lyophilized for DNA extraction using the cetyl trimethyl-ammonium bromide method (Zhao and Pan, 2004).

Polymerase chain reaction (PCR) analyses for SRAP (Li and Quiros, 2001) and SSR markers were performed in 10- $\mu \mathrm{L}$ volumes of a uniform reaction mixture [i.e., SRAP: $1 \mu \mathrm{L}$ 10X PCR commercial buffer, $20 \mathrm{mM} \mathrm{MgCl}, 2 \mathrm{mM}$ dNTPs, 15-20 ng DNA, $2.5 \mu \mathrm{M}$ of each primer, and 1.75 U Taq DNA polymerase (Shanghai Promega); SSR: $1 \mu \mathrm{L}$ 10X PCR commercial buffer, $20 \mathrm{mM} \mathrm{MgCl}, 2 \mathrm{mM}$ dNTPs, 15-20 ng DNA, $2.5 \mu \mathrm{M}$ of each primer, and 1 U Taq DNA polymerase (Shanghai Promega)], incorporating $10 \mu \mathrm{L}$ light-weight mineral oil overlay. The amplified products were resolved on $4.0 \%$ denatured polyacrylamide gels $(6.0 \%$ SSR; Life Technologies, Gaithersburg, MD, USA) by silver staining. The gels were visualized using an Image Scanner III.

\section{Mapping and QTL analysis}

Linkage mapping was performed using the JoinMap 3.0 software (van Ooijen and Voorrips, 2001) based on the $F_{2}$ data, with a log-likelihood threshold $\geq 3.0$ and the Kosambi mapping function (Kosambi, 1944). QTLs were conducted for the $F_{2: 3}$ families, and the $M_{22}$ and $\mathrm{M}_{14}$ populations using WinQTLCart 2.5 (Zeng, 1993; Christopher et al., 2002).

\section{Data analysis method}

The genetic analysis was carried out using the major gene and polygene models (Zhang et al., 2000). Least-square means and a column diagram of frequencies for traits were calculated according to the SPSS16.0 software.

\section{RESULTS}

\section{Distribution of the low-light tolerance index in cucumber}

The degree of damage to most plants was lower, higher, and advisable in the lowlight tolerant line $\mathrm{M}_{22}\left(\mathrm{P}_{1}\right)$, low-light sensitive line $\mathrm{M}_{14}\left(\mathrm{P}_{2}\right)$, and $\mathrm{F}_{1}$ group, respectively (Table 1). The variation in the degree of damage (i.e., grade) in the cross $\mathrm{P}_{1} \times \mathrm{P}_{2}$ was $0-4$ and exceeded the range of its parents, which showed that favorable genes and leaky genes had a scattered distribution and could form transgressive segregation lines via genetic recombination. 
Table 1. Frequency of low-light tolerance index for 6 generations.

\begin{tabular}{|c|c|c|c|c|c|c|}
\hline Generation & 0 grade & 1st grade & 2nd grade & 3rd grade & 4th grade & $\mathrm{N}$ \\
\hline$\overline{P_{1}}$ & 8 & 8 & 10 & 4 & & 30 \\
\hline $\mathrm{P}_{2}$ & & 2 & 6 & 12 & 10 & 30 \\
\hline $\mathrm{F}_{1}^{2}$ & 4 & 8 & 7 & 7 & 4 & 30 \\
\hline $\mathrm{F}_{2}$ & 13 & 20 & 25 & 48 & 14 & 120 \\
\hline $\mathrm{B}_{1}^{2}$ & 7 & 11 & 19 & 16 & 7 & 60 \\
\hline $\mathrm{B}_{2}$ & 2 & 8 & 17 & 28 & 5 & 60 \\
\hline
\end{tabular}

\section{Phenotypic variation in the low-light tolerance index in the $\mathrm{F}_{2: 3}$ lines}

In the $\mathrm{F}_{2: 3}$ lines, the total mean for the low-light tolerance index in the $\mathrm{S}$ was greater than that in the $\mathrm{A}$ (Table 2). The low-light tolerance index of the lines and seasons significantly or highly significantly differed.

The mean value for the low-light tolerance index in the $\mathrm{F}_{2: 3}$ lines (Table 3) was intermediate between that of its parents, and the coefficients of variation were 30.9 and $32.1 \%$ in the $\mathrm{S}$ and A, respectively. The standard deviations for the $\mathrm{S}$ and $\mathrm{A}$ were $<1.0$.

Table 2. Variance in low-light tolerance index of the $\mathrm{F}_{2: 3}$ lines across 2 seasons.

\begin{tabular}{lccc}
\hline Source & DF & MS & F value \\
\hline $\mathrm{F}_{2: 3}$ family & 122 & 1335.137 & $6.808^{*}$ \\
Season & 1 & 2226.215 & $11.352^{* *}$ \\
Error & 122 & 196.0992 & \\
Total variance & 245 & & \\
\hline
\end{tabular}

*Significant difference at $\mathrm{P}<0.05$ level. ${ }^{* *}$ Significant difference at $\mathrm{P}<0.01$ level.

Table 3. Variance analysis of low-light tolerance index (LLTI) in the $\mathrm{F}_{2: 3}$ lines.

\begin{tabular}{lccccc}
\hline Trait & Ranges & Means & Variance & Standard deviation & CV (\%) \\
\hline LLTI_spring & $1.43-3.88$ & 2.17 & 0.449 & 0.670 & 30.9 \\
LLTI_autumn & $1.00-4.05$ & 2.00 & 0.412 & 0.642 & 32.1 \\
\hline
\end{tabular}

\section{Normal sex distribution test for the low-light tolerance index in the $F_{2: 3}$ lines}

Results of the normal sex distribution test (Figure 1) showed that the low-light tolerance index for the $\mathrm{S}$ and $\mathrm{A}$ conformed to the normal and skewed normal distributions, respectively. Thus, segregation traits may be multi-gene distribution characteristics, and the lowlight tolerance index distribution in the $\mathrm{S}$ and A conformed to the QTL mapping requirements.

\section{Genetic analysis of low-light tolerance for cucumber seedlings}

The $\mathrm{ABC}$ scale genetic testing was adopted for the genetic analysis of low-light tolerance in cucumber seedlings, and the $P$ values of 3 models were $>0.05$, indicating that the inheritance of low-light tolerance is in accordance with the additive-dominant model (Table 4).

Gene effects of low-light tolerance are listed in Table 5, and the total mean values, 
additive effects, and dominant effects were $1.973,0.385$, and -1.917 , respectively, which indicates that heredity of low-light tolerance exhibits positive addictive and negative dominant effects. Moreover, the mean dominance degree $\left[(\mathrm{H} / \mathrm{D})^{1 / 2}\right]$ was 2.230 , suggesting that the inheritance of low-light tolerance exhibits negative super-dominant and mainly dominant effects, with the effect of additive interactions.

Furthermore, the main gene and polygenic inheritance analyses were adopted in this study. The results showed that low-light tolerance is controlled by an additive-dominant polygene, and there were epistasis in these genes. Estimated values of the genetic parameters for the low-light intensity tolerance index in Table 6 show that the polygenic inheritance rate of the separate generations were $>30 \%$; the highest rate was observed in the $\mathrm{F}_{2}$ generation (i.e., $39.3 \%)$. The addictive effect of the polygenes was 0.517 , and the dominant effect value was -1.267. Each of these values were small, which indicates that there are no significant differences in the gene interactions. The environmental variance, accounting for the phenotypic variance ratio of the $\mathrm{F}_{2}$ generation, returned the lowest value (i.e., 30.36\%), suggesting that inheritance of low-light tolerance is rarely impacted by the environment.
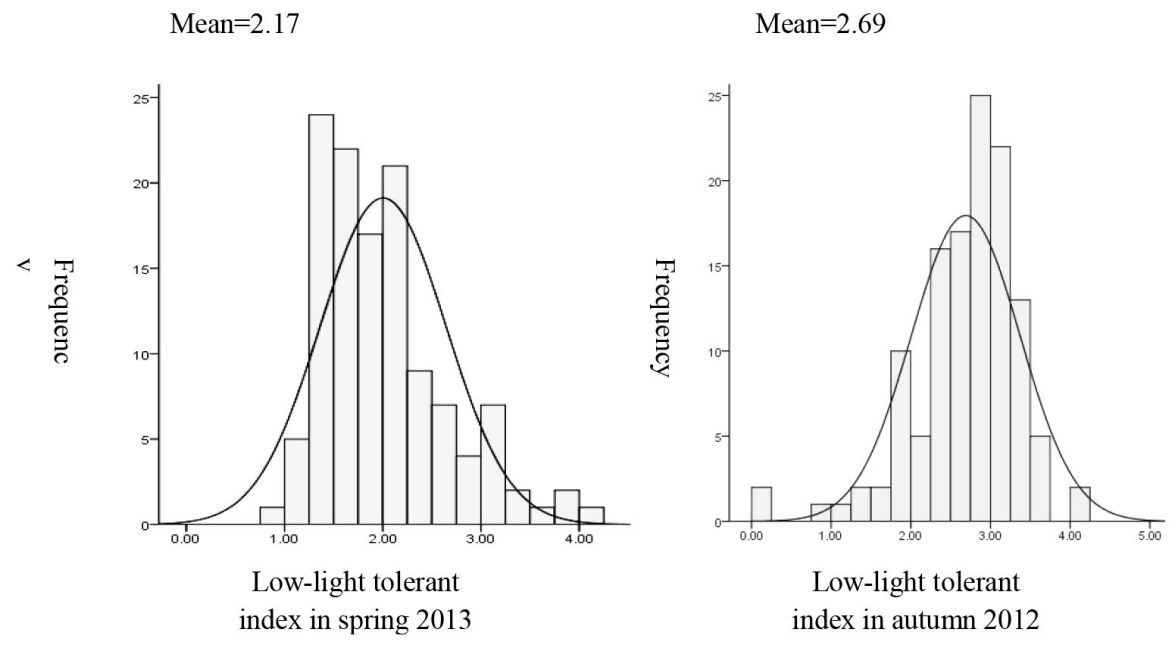

Figure 1. Normality test of the low-light tolerance index.

Table 4. ABC scale test for low-light tolerance.

\begin{tabular}{lrccc}
\hline Model & Mean & SE & $t$ value & P value \\
\hline A & -0.980 & 0.802 & 1.222 & 0.275 \\
B & 0.470 & 0.975 & 0.482 & 0.634 \\
C & 0.210 & 2.375 & 0.088 & 0.892 \\
\hline
\end{tabular}

Table 5. Genetic effects and estimated values of low-light tolerance in cucumber.

\begin{tabular}{lccccc}
\hline Genetic effect & $\begin{array}{c}\text { Estimated } \\
\text { value }\end{array}$ & $\begin{array}{c}\text { Standard } \\
\text { error }\end{array}$ & $\begin{array}{c}\text { Mean dominance } \\
\text { degree }\left[(\mathrm{H} / \mathrm{D})^{1 / 2}\right]\end{array}$ & $\begin{array}{c}\text { Broad-sense } \\
\text { heritability } \mathrm{h}_{\mathrm{B}}{ }^{2}(\%)\end{array}$ & $\begin{array}{c}\text { Narrow-sense } \\
\text { heritability } \mathrm{h}_{\mathrm{N}}{ }^{2}(\%)\end{array}$ \\
\hline Total mean & 1.973 & 2.148 & 2.230 & 73.71 & 28.83 \\
Additive effect & 0.385 & 1.865 & & & \\
Dominant effect & -1.917 & 4.763 & & & \\
\hline
\end{tabular}


Table 6. Estimated values of genetic parameters of low-light tolerance.

\begin{tabular}{lccccc}
\hline 1st parameter & Estimated value & 2nd parameter & \multicolumn{3}{c}{ Estimated values } \\
\cline { 4 - 6 } & & & $\mathrm{B}_{1}$ & $\mathrm{~B}_{2}$ & $\mathrm{~F}_{2}$ \\
\hline Total mean & 2.08 & $\sigma^{21}$ & 29.18 & 22.62 & 39.30 \\
Additive effect & 0.517 & $\sigma^{{ }^{2}{ }^{2}}$ & 17.25 & 10.70 & 27.37 \\
Dominant effect & -1.267 & $\sigma^{2}{ }^{2}$ & 11.93 & 11.93 & 11.93 \\
& & $\mathrm{~h}^{2}{ }^{2}(\%)^{4}$ & 59.12 & 47.27 & 69.64 \\
& & $1-\mathrm{h}^{2}{ }^{2}(\%)$ & 40.88 & 52.73 & 30.36 \\
\hline
\end{tabular}

${ }^{1} \sigma_{\mathrm{p}}^{2}$, phenotypic variance. ${ }^{2} \sigma^{2}{ }_{\mathrm{mg}}$, major gene variance. ${ }^{3} \sigma_{\mathrm{e}}^{2}$, environmental variance. ${ }^{4} \mathrm{~h}_{\mathrm{pg}}{ }^{2}$, polygene heritability value.

\section{QTL analysis of low-light tolerance for cucumber seedlings}

Five QTLs related to the low-light tolerance index were detected in the S and A, including 2 QTLs (i.e., Llti1.1 and Llti1.2) on the first linkage group, with variances of 6.0 and $9.5 \%$ , positive addictive effect values of 10.5 and 9.5 , and negative dominant effect values of -0.09 and -0.07 , respectively. Three QTLs (Llti2.1, Llti2.1, and Llti2.1) were mapped on the second linkage group, with variances of 10.1-14.0\%; addictive effect values of 8.07, -0.06, and -2.1; and dominant effect values of $0.06,0.09$, and 0.45 , respectively (Figure 2; Table 7).

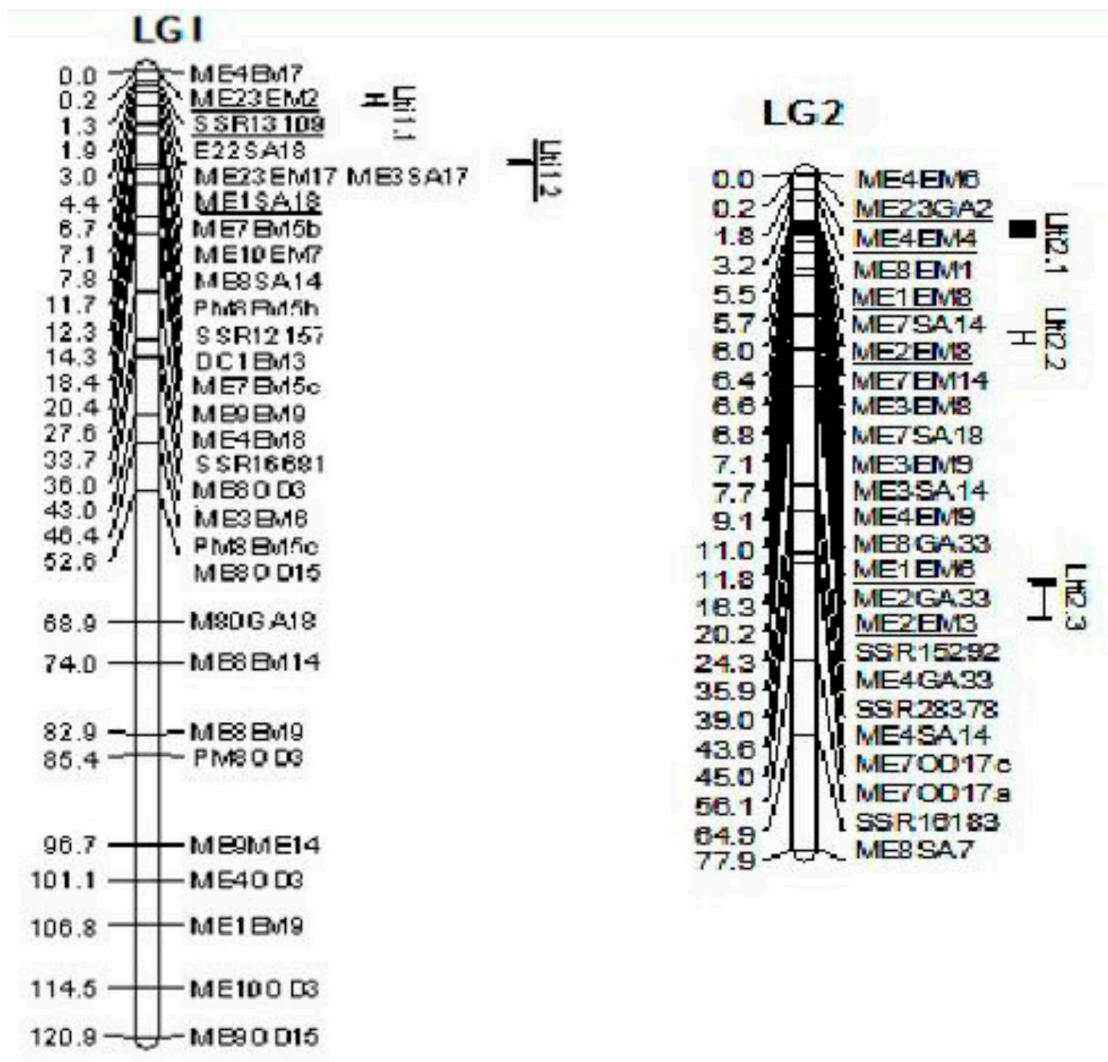

Figure 2. Quantitative trait loci of low-light tolerance in cucumber. 
Table 7. Positions, intervals, effects, and varieties of quantitative trait loci (QTLs) for low-light tolerance.

\begin{tabular}{lllccccc}
\hline Trait/QTL & Linkage group & Flanking locus & Position $(\mathrm{cM})^{2}$ & LOD & Variety R $^{2}(\%)$ & Addictive effect $^{3}$ & Dominant effect $^{4}$ \\
\hline Llti1.1 & 1 & ME23EM2-SSR13109 & 1.1 & 13.2 & 6.0 & 10.5 & -0.09 \\
Llti1.2 & 1 & SSR13109-ME1SA18 & 1.8 & 12.7 & 9.6 & 9.5 & -0.07 \\
Llti2.1 & 2 & ME23GA2-ME4EM4 & 1.3 & 8.9 & 14.0 & 8.07 & 0.06 \\
Llti2.2 & 2 & ME1EM8-ME2EM8 & 1.9 & 10.1 & 13.6 & -0.06 & 0.09 \\
Llti2.3 & 2 & ME1EM6-ME2EM3 & 12.3 & 7.9 & 10.1 & -2.1 & 0.45 \\
\hline
\end{tabular}

${ }^{1}$ Number + QTL serial number. ${ }^{2}$ Position of the LOD peak value. ${ }^{3}$ Positive value is the add-effect derived from the parental line $\mathrm{M}_{22}$ and the negative value is the add-effect derived from the parental line $\mathrm{M}_{14} \cdot{ }^{4}$ Positive value is the trait controlled by gene likely to one of parental line $\mathrm{M}_{22}$ and the negative value is the trait controlled by gene likely to one of parental line $\mathrm{M}_{14}$.

\section{DISCUSSION}

Low-light tolerance in cucumber plants is a quantitative trait, and the low-light tolerance index is a comprehensive and effective evaluation of low-light tolerance ( $\mathrm{Li}$ et al., 2009a). Quantitative traits of the plant are controlled by a few major genes or a large polygene, and the effects of those genes differ (Wang et al., 2008).

An in-depth and comprehensive elaboration on the genetic characteristics of low-light tolerance for cucumber is given in this paper. The results of 2 genetic methods showed that the heredity of low-light tolerance is controlled by major genes and a mini-polygene, and they fit to an additive-dominance or additive-dominance-epistasis polygene model. The genetic model results are similar to those of a prior study investigating traits related to low-light tolerance (Li et al., 2009c). In addition, 5 QTLs were related to the low-light tolerance index in both the $\mathrm{S}$ and $\mathrm{A}$, supporting the hypothesis that low-light tolerance is controlled by a major gene and a mini-polygene.

In this study, among the additive effect values of the 5 QTLs, 3 and 2 QTLs were positive and negative, respectively, indicating the additive and subtractive effects of the genes (Gong et al., 2001). Moreover, gene cluster regions were identified, such as QTL Llti2.2 in the interval ME1EM8-ME2EM8, since Chla2.1 for ch1.a content and Chla $+b 2.2$ for ch1 $a+b$ content were also controlled by this interval. QTL Llti2.3 was detected in the interval ME1EM6ME2EM3; 2 QTLs controlling ch1.a content and hypocotyl length were identified in the interval ME1EM6-ME2EM3 in each season. This result is similar to that of a prior report on traits of low-light tolerance in cucumber (Li et al., 2010). Gene cluster regions have been reported in many studies (Moynihan et al., 2009; Sorice et al., 2011). QTLs gathered in an identical region but controlled different traits, which may indicate close linkage, and pleiotropism or physiological associations. Thus, 2 closely adjacent regions on the 2 nd linkage group may have a more significant role in the gene expression of low-light tolerance or related traits. Therefore, we presumed that the QTLs detected in the 2 seasons would be the genes controlling low-light tolerance.

Several factors for cucumber low-light tolerance were analyzed, and QTL mapping was performed. First, the SRAP markers can now be closely linked to the 5 QTLs and transformed into SCAR markers to facilitate breeding of plants with low-light resistance (Ren et al., 2012). Second, molecular markers constitute an efficient tool for indirect selection in plant breeding (Lecomte et al., 2004). Marker-assisted selection (MAS) could aggregate QTLs of low-light tolerance from different cucumber lines into a single line. Different environments affected this trait, and the selection of this trait by phenotypic grade was not feasible. Using 
MAS, seedlings were selected based on molecular markers linked to low-light tolerance. They have been widely used for following the introgression of monogenic traits, such as disease resistance (Yu et al., 2000; Singh et al., 2001). This action can shorten the breeding process and increase breeding efficiency. Further studies can contribute to an increase in the efficiency of cucumber breeding in the future.

\section{ACKNOWLEDGMENTS}

We greatly thank professors Si and Cai for their comments and suggestions on the earlier version of the manuscript. Research supported by a grant from Dr. Start-up fund of Heilongjiang Bayi Agricultural University and Heilongjiang Agricultural Reclamation Administration Research Project (\#HNKXIV-06-03a1).

\section{REFERENCES}

Christopher JB and Bruce S (2004). Weir and Zhao-Bang Zeng. A reference manual and tutorial for QTL mapping. Bioinformatics Research Center, Department of Statistics, North Carolina State University, Raleigh, NC 276957566.

Christopher JB, Bruce SW and Zeng ZB (2002). A Reference Manual and Tutorial for QTL Mapping. Bioinformatics Research Center, Department of Statistics, North Carolina State University, Raleigh, 27695-7566.

Fazio G, Staub JE and Stevens MR (2003). Genetic mapping and QTL analysis of horticultural traits in cucumber (Cucumis sativus L.) using recombinant inbred lines. Theor. Appl. Genet. 107: 864-874.

Gong JM, Zheng X, Du B, Qian Q, et al. (2001). Comparative study of QTLs for agronomic traits of rice (Oryza sativa L.) between salt stress and nonstress environment. Sci. China C Life Sci. 44: 73-82.

Kosambi DD (1944). The estimation of map distances from recombination values. Ann. Eugenics 12: 172-175.

Krakowsky MD, Lee M, Woodman-Clikeman WL, Long MJ, et al. (2004). QTL mapping of resistance to stalk tunneling by the European corn borer in RILs of maize population B73 x De811. Crop Sci. 44: 274-282.

Lecomte L, Duffé P, Buret M, Servin B, et al. (2004). Marker-assisted introgression of five QTLs controlling fruit quality traits into three tomato lines revealed interactions between QTLs and genetic backgrounds. Theor. Appl. Genet. 109: 658-668.

Li DD, Si LT, Niu HCh, Gao LN, et al. (2009a). Multiple statistics analysis of low light tolerance in cucumber (Cucumis sativus L.). Acta Hort. Sin. 36: 501-506.

Li DD, Si LT, Li J, Jin ZA, et al. (2009b). Genetic analysis on chlorophyll contents of cucumber seedling under low light. Acta Agr. Boreali-Sinica 24: 1-4.

Li DD, Si LT, Luo XM and Li T (2009c). Genetic model analysis on traits of cucumber seedling under low light stress. $J$. North. A\&F Univ. 11: 113-119.

Li DD, Si LT, Zhang GY, Zhang SJ, et al. (2010). Quantitative trait loci analysis for chlorophyll content of cucumber (Cucumis sativus L.) seedlings under low-light stress. AFR. J.Biotechnol. 9: 4692-4699.

Li G and Quiros CF (2001). Sequence-related amplified polymorphism (SRAP), a new marker system based on a simple PCR reaction: its application to mapping and gene tagging in Brassica. Theor. Appl. Genet. 103: 455-461.

Li JW, An HW, Yu JZh, Mao GZh, et al. (2006). Genetic analysis of several physiological indicators under low-light in cucumber seedling stage. Sci. Agric. Shang. 22: 25-30.

Li XZ, Yuan XJ, Jiang S, Pan JS, et al. (2008). Detecting QTLs for plant architecture traits in cucumber (Cucumis sativus L.). Breeding Sci. 58: 453-460.

Liebig HP and Krug H (1991). Response of cucumber to climate. Acta Hort. Sin. 287: 47-50.

Liu DJ, Ieng GJ and Ye YL (2009). Identification on chilling risistance of snap bean seedling. China Vegetables 6: 55-58.

Liu L, Cai R, Yuan X, He H, et al. (2008). QTL molecular marker location of powdery mildew resistance in cucumber (Cucumis sativus L.). Sci. China C Life Sci. 51: 1003-1008.

Ma DH, Pang JA, Huo ZhR, et al. (1997). Effects of weak light treatment on the photosynthesis and respiration of cucumber seedlings. Acta Agricult. Univ. Henanensis. 9: 248-254.

Moynihan JA, Morrissey JP, Coppoolse ER, Stiekema WJ, et al. (2009). Evolutionary history of the $p h l$ gene cluster in the plant-associated bacterium Pseudomonas fluorescens. Appl. Environ. Microbiol. 75: 2122-2131.

Ren N, Liu J, Yang D, Chen J, et al. (2012). Sequence-related amplified polymorphism (SRAP) marker as a new method 
for identification of endophytic fungi from Taxus. World J. Microbiol. Biotechnol. 28: 215-221.

Ren Y, Zhang Z, Liu J, Staub JE, et al. (2009). An integrated genetic and cytogenetic map of the cucumber genome. PLoS One 4: e5795.

Singh S, Sidhu JS, Huang N, Vikal Y, et al. (2001). Pyramiding three bacterial blight resistance genes (xa5, xa13 and xa21) using marker-assisted selection into indica rice cultivar PR106. Theor. Appl. Genet. 102: 1011-1015.

Sorice R, Bione S, Sansanelli S, Ulivi S, et al. (2011). Association of a variant in the CHRNA5-A3-B4 gene cluster region to heavy smoking in the Italian population. Eur. J. Hum. Genet. 19: 593-6.

Tang D, Wu W, Li W, Lu H, et al. (2000). Mapping of QTLs conferring resistance to bacterial leaf streak in rice. Theor. Appl. Genet. 101: 286-291.

Wang F, Wang G, Li X, Huang J, et al. (2008). Heredity, physiology and mapping of a chlorophyll content gene of rice (Oryza sativa L.). J. Plant Physiol. 165: 324-330.

Yu K, Park SJ and Pysa V (2000). Marker-assisted selection of common beans for resistance to common bacterial blight: efficacy and economics. Plant Breeding 119: 411-415.

van Ooijen JW and Voorrips RE (2001). JoinMap ${ }^{\circledR}$ version 3.0: software for the calculation of genetic linkage maps. Plant Research International, Wageningen.

Zeng ZB (1993). Theoretical basis of separation of multiple linked gene effects on mapping quantitative trait loci. Proc. Natl. Acad. Sci. U S A 90: 10972-10976.

Zhang HY, Chen QJ and Wang YJ (2004). Identification of QTLs for cucumber poorlight tolerance. Mol. Plant Breeding 2: 795-799.

Zhang WW, He H, Guan Y, Du H, et al. (2010). Identification and mapping of molecular markers linked to the tuberculate fruit gene in the cucumber (Cucumis sativus L.). Theor. Appl. Genet. 120: 645-654.

Zhang YM, Gai JY and Wang JK (2000). Identification of two major genes plus polygenes mixed inheritance model of quantitative traits in $\mathrm{B}_{1}$ and $\mathrm{B}_{2}$ and $\mathrm{F}_{2}$. J. Biomathemat. 15: 358-366.

Zhao WG and Pan YL (2004). Genetic diversity of genus Morus revealed by RAPD markers in China. Int. J. Agric. Biol. 6: 950-954. 